\title{
Progression of Pregnancy Induced Diabetes Mellitus to type two Diabetes Mellitus, an Ambidirectional cohort study.
}

berhanu elfu feleke ( $\square$ elfufeleke@gmail.com )

Bahir Dar University https://orcid.org/0000-0001-9251-3337

Teferi Elfu Feleke

Wolkite University

Melkamu Beyene Kassahun

Amhara National Regional Health Bureau

Wondemu Gebrekirose Adane

Global Tuberculosis program

Desalegn Nigatu Achenefe

Bahir Dar University

Abere Genetu

Bahir Dar University

Azezu Asres Nigussie

Bahir Dar University

Hailemariam Awoke Engedaw

Bahir Dar University

Research article

Keywords: Glucose intolerance, pregnancy induced diabetes mellitus, progression, type 2 DM

Posted Date: June 8th, 2020

DOI: https://doi.org/10.21203/rs.3.rs-30572/v1

License: (c) (1) This work is licensed under a Creative Commons Attribution 4.0 International License.

Read Full License

Version of Record: A version of this preprint was published at Primary Care Diabetes on June 1st, 2021. See the published version at https://doi.org/10.1016/j.pcd.2020.11.016. 


\section{Abstract}

\section{Introduction:}

Diabetes Mellitus (DM) is a metabolic disorder characterized by elevated level of blood glucose. It affects more than 422 million people globally. In resource limited settings, the progression of gestational diabetes (GDM) to DM was not well investigated and this research work was conducted to estimate the incidence of DM after GDM and their predictors in resource limited settings.

\section{Methods}

Both retrospective and Prospective cohort studies were implemented from January 2010 until December 2019. The data were collected using patients chart review, interview and collecting blood sample. Initially, baseline data were collected from GDM and GDM free women and update data were collected every 3 months. Clinical nurses were used to extract the necessary data from medical charts and to collect the data using patient interview. Laboratory technologists were used to measure the blood glucose level of the study participants. The study was conducted in pregnant women presenting themselves in the referral hospitals of Amhara regional state. The sample size was calculated using Epi-info software. Descriptive statistics were used to describe the profile of study participants. Kaplan Meier survival curve and life-table were used to estimate the survivals of study participants. Incidence density was used to estimate the incidence of DM. Cox regression was used to identify the predictors DM.

\section{Results}

A total of 4892 women were followed giving for the response rate of $88.62 \%$. The mean age of study participants at the start of the study was 28.34 years with standard deviation [SD] \pm 7.48 years. DM was associated with Gestational diabetes mellitus [AHR(adjusted hazard ratio) ;2.53, 95\% Cl: 2.14-2.99], Frequency of breastfeeding [AHR; $0.72,95 \% \mathrm{Cl}$ : 0.69-0.74], age [AHR; $1.04,95 \%$ Cl: 1.03-1.05], Parity [AHR; 1.14, 95\% Cl: 1.07-1.21], Regular physical exercise [AHR; 0.45, 95\% Cl: 0.37-0.55], Family history of DM [AHR; 2.04, 95\% Cl: 1.76-2.37],Stillbirth increases [AHR;1.67: 95\% Cl: 1.34-2.07], Abortion [AHR; 2.64, 95\%Cl: 2.25-3.09].

\section{Conclusion}

The progression of GDM to DM was very high and special follow up should be implemented for women with a history of abortion, stillbirth, and family history of DM.

\section{Introduction}


Diabetes mellitus (DM) is a metabolic disorder characterized by impaired metabolism of glucose fat and proteins. It is generally classified as Gestational diabetes mellitus (GDM), type 1 diabetes mellitus, and type two diabetes mellitus. GDM is a high blood glucose level first detected in pregnancy and it disappears after 42 days post-partum. Type $1 \mathrm{DM}$ occurs when the pancreas produces little or no insulin and common in childhood. Type two diabetes mellitus is the most common type of DM and characterized by insulin resistance and latter on insulin deficiency [1-3].

World health organization (WHO) estimates that about 422 million people are diabetes and its prevalence will increase with a high rate in the coming years. The number of DM patients increase by four folds since 1980. Yearly, 1.6 million people were dying as a result of DM. The mortality and morbidity of DM were higher in low and middle- income countries [4].

DM has acute and chronic complications; the acute complication resulted from the mismatch between the available insulin and its demand and includes hypoglycemia, hyperosmolar hyperglycemic state (HHS), and diabetes ketoacidosis (DKA) [5]. Chronic complication attacks years later and it affects all parts of the body, particularly affecting the eyes, nerves, kidneys, feet, arm, mouth, and skin [6].

The expert recommends using one of the following modalities to diagnose DM; fasting blood glucose level (>126 mg/dl), random blood glucose level (> $200 \mathrm{mg} / \mathrm{dl})$, measuring glycated hemoglobin (HbA1c > 6.5 at two different spots) or oral glucose tolerance tests at two different spots [7].

In resource-limited settings, the progression of GDM to DM was not well investigated and this research work was conducted to estimate the incidence of DM after GDM and their predictors in resource-limited settings.

\section{Methods And Materials}

Both retrospective and Prospective cohort studies were implemented. The study was conducted starting from January 2010 until December 2019; starting from January 2010 to February 2015 the study participants were followed retrospectively, meaning reviewing the medical charts. And starting from March 2015 to December 2019 the study participant's status was checked every 3 months prospectively. A Simple random sampling technique was used to select both GDM and GDM free women using their registration chart ID as a sampling frame. The data were collected using patients chart review, interview and collecting a blood sample. Initially, baseline data were collected from GDM, and GDM free women and update data were collected every 3 months. The DM status of each study participant was checked every 3 months using the random plasma glucose (RPG) test [8]. Each study participant was followed for a total of 10 years (January 2010 to December 2019).The event of this study was DM. Study participants withdrew from the study before the event was considered as censored. Clinical nurses were used to extracting the necessary data from medical charts and to collect the data using the patient interviews. Laboratory technologists were used to measuring the blood glucose level of the study participants. 
The International Physical Activity Questionnaire tool (IPAQ) was used to measure regular physical [9]. The random blood glucose level was measured using Random Plasma Glucose (RPG) test adhering to the standard operating procedures [8]. The whole data collection procedures were closely supervised.

Pregnant women receiving antenatal care in the year 2010 and diagnosed GDM were considered as an exposed group. Pregnant women receiving the ANC service and declared GDM free in the year 2010 were considered as non-exposed. For the first phase (starting from January 2010 to February 2015), study participants were followed retrospectively from their medical chart. For the second phase from March 2015 to December 2019, the study participants were followed prospectively. The study was conducted in pregnant women presenting themselves in the referral hospitals of Amhara regional state (Gondar university hospital, Felegehiwote referral hospital, Debreberhane hospital, Dessie referral hospital, and Debremarkose referral hospital) DM was diagnosed using American diabetes association, random blood sugar $>200 \mathrm{mg} / \mathrm{dl}$ at two different spots was labeled as DM patient [7]. The sources of the data were hospital registers and primary data from each participant. To increase the response rate of the study, each study participant was informed about the study and its merits to the community.

The sample size was calculated using Epi-info software using the assumption of $95 \% \mathrm{Cl}, 90 \%$ power, the ten-year risk of diabetes mellitus after gestational diabetes of 50\% [10], the ratio of women with GDM and GDM free of 1: 2, $15 \%$ non-response rate gives 1840 women with GDM and 3,680 women free from GDM.

Data were analyzed using STATA software version 14. Descriptive statistics were used to describe the profile of the study participants. Kaplan Meier survival curve and life-table were used to estimate the survivals of study participants. Incidence density was used to estimate the incidence of DM. Cox regression was used to identify the predictor's DM, Adjusted Hazard Ratio (AHR) with their $95 \% \mathrm{Cl}$ were used to declare the determinants. Multiple imputations were used to handle the missing data [11].

Ethical clearance was obtained from Bahir Dar University College of medicine and health science ethical review board with an ethical approval number of CMHS/IRB/93/2014. A support letter was obtained from the Amhara regional state health bureau. A permission letter was obtained from each hospital. Written informed consent was obtained from each study participant. Pretest and posttest counseling was given for each study participant. A study participant diagnosed with DM was linked to the chronic care.

\section{Results}

A total of 4,892 women were followed giving for the response rate of $88.62 \%$, the records of 324 study participants were incomplete, 108 study participants changed their resident and 196 study participants were not volunteer to participate in the study. The mean age of study participants at the start of the study was 28.34 years with standard deviation [SD] \pm 7.48 years (Table 1 ). 
Table 1

Profile of the study participants $(n=4892)$

\begin{tabular}{|c|c|c|c|c|c|c|}
\hline \multirow{2}{*}{$\begin{array}{l}\text { Serial } \\
\text { Number }\end{array}$} & \multirow[t]{2}{*}{ Variables } & & \multicolumn{2}{|l|}{ GDM } & \multicolumn{2}{|c|}{ Free from GDM } \\
\hline & & & Frequency & Percentage & Frequency & Percentage \\
\hline \multirow[t]{2}{*}{1.} & \multirow{2}{*}{$\begin{array}{l}\text { Family history of } \\
\text { DM }\end{array}$} & Present & 217 & 65.2 & 116 & 34.8 \\
\hline & & Absent & 1432 & 31.4 & 3127 & 68.6 \\
\hline \multirow[t]{2}{*}{3.} & \multirow{2}{*}{$\begin{array}{l}\text { Regular physical } \\
\text { exercise }\end{array}$} & Present & 421 & 24.5 & 1295 & 75.5 \\
\hline & & Absent & 1228 & 38.7 & 1948 & 61.3 \\
\hline \multirow[t]{4}{*}{5.} & \multirow[t]{2}{*}{ History of abortion } & Present & 158 & 48.9 & 165 & 51.1 \\
\hline & & Absent & 1491 & 32.6 & 3078 & 67.4 \\
\hline & \multirow[t]{2}{*}{ History of stillbirth } & Present & 105 & 72.9 & 39 & 27.1 \\
\hline & & Absent & 1544 & 32.5 & 3204 & 67.5 \\
\hline
\end{tabular}

\section{Incidence Of Diabetes Mellitus}

The incidence of DM in women with a history of GDM was 705/10355 person year; that means, if we follow 10355 GDM women for a year, 705 women will develop DM at the end of the year.

The incidence of diabetes mellitus for women free from GDM was 349/25501 person year; if we follow 25501 GDM free women for a year, 349 women will develop DM at the end of the year (Fig. 1). 
Table 2

Life table for DM $(\mathrm{n}=4892)$

\begin{tabular}{|llllllll|}
\hline Interval in months & Total & DM & Lost & Survival & Standard error & $95 \%$ Cl & \\
\cline { 7 - 8 } & & & & & & Lower limit & Upper limit \\
\hline $48-49$ & 4892 & 51 & 0 & 0.9896 & 0.0015 & 0.9863 & 0.9921 \\
\hline $57-52$ & 4841 & 24 & 0 & 0.9847 & 0.0018 & 0.9808 & 0.9878 \\
\hline $60-61$ & 4817 & 124 & 0 & 0.9593 & 0.0028 & 0.9534 & 0.9645 \\
\hline $63-64$ & 4693 & 174 & 0 & 0.9238 & 0.0038 & 0.9160 & 0.9309 \\
\hline $66-67$ & 4519 & 0 & 205 & 0.9238 & 0.0038 & 0.9160 & 0.9309 \\
\hline $69-70$ & 4314 & 88 & 0 & 0.9049 & 0.0042 & 0.8963 & 0.9128 \\
\hline $72-73$ & 4226 & 0 & 222 & 0.9049 & 0.0042 & 0.8963 & 0.9128 \\
\hline $75-76$ & 4004 & 112 & 279 & 0.8787 & 0.0048 & 0.8690 & 0.8877 \\
\hline $81-82$ & 3613 & 242 & 0 & 0.8198 & 0.0058 & 0.8082 & 0.8308 \\
\hline $84-85$ & 3371 & 24 & 0 & 0.8140 & 0.0058 & 0.8022 & 0.8251 \\
\hline $87-88$ & 3347 & 0 & 443 & 0.8140 & 0.0058 & 0.8022 & 0.8251 \\
\hline $94-95$ & 2904 & 133 & 0 & 0.7767 & 0.0064 & 0.7639 & 0.7890 \\
\hline $97-98$ & 2771 & 0 & 644 & 0.7767 & 0.0064 & 0.7639 & 0.7890 \\
\hline $99-100$ & 2127 & 0 & 788 & 0.7767 & 0.0064 & 0.7639 & 0.7890 \\
\hline $104-105$ & 1339 & 29 & 0 & 0.7599 & 0.0070 & 0.7459 & 0.7733 \\
\hline $108-109$ & 1310 & 0 & 826 & 0.7599 & 0.0070 & 0.7459 & 0.7733 \\
\hline
\end{tabular}

After adjusting for age, history of abortion, history of stillbirth, frequency of breastfeeding, regular physical exercise, parity after GDM, family history of DM, GDM, and other chronic illnesses; DM was associated with a history of abortion, history of stillbirth, regular physical exercise, family history of DM, age, GDM, frequency of breastfeeding (Table 3). 
Table 3

Cox regression output for the determinants of DM ( $N=4892)$.

\begin{tabular}{|c|c|c|c|c|c|c|}
\hline \multirow[t]{2}{*}{ Variables } & \multirow[t]{2}{*}{ Hazard Ratio } & \multirow[t]{2}{*}{ Std. Err. } & \multirow[t]{2}{*}{$\mathbf{z}$} & \multirow[t]{2}{*}{$P>z$} & \multicolumn{2}{|c|}{$95 \% \mathrm{Cl}$ for $\mathrm{HR}$} \\
\hline & & & & & Lower & Upper \\
\hline Frequency of breast feeding & 0.72 & 0.01 & -20.26 & $<0.01$ & 0.70 & 0.74 \\
\hline Age & 1.04 & 0.00 & 9.86 & $<0.01$ & 1.04 & 1.05 \\
\hline Parity & 1.14 & 0.04 & 4.00 & $<0.01$ & 1.07 & 1.21 \\
\hline GDM & 2.53 & 0.22 & 10.89 & $<0.01$ & 2.14 & 2.99 \\
\hline Regular physical activity & 0.45 & 0.05 & -7.71 & $<0.01$ & 0.37 & 0.55 \\
\hline Family history of DM & 2.04 & 0.15 & 9.43 & $<0.01$ & 1.76 & 2.37 \\
\hline History of stillbirth & 1.67 & 0.18 & 4.62 & $<0.01$ & 1.34 & 2.07 \\
\hline History of abortion & 2.64 & 0.21 & 12.04 & $<0.01$ & 2.25 & 3.09 \\
\hline
\end{tabular}

\section{Discussion}

Gestational diabetes increases the risk of DM by 2.53 folds higher [AHR; $2.53,95 \% \mathrm{Cl}: 2.14-2.99$ ]. The progression of GDM to DM is 705/10355 person-year, if we follow 10,355 GDM women for a year, 705 women will develop DM at the end of the year. This finding agrees with finding from Sri-Lanka [12]. This is due to the linear associations of gestational diabetes mellitus and peripheral insulin resistance [13].

The risk of diabetes mellitus decreases by $28 \%$ per unit increase in the frequency of breastfeeding per 24 hours [AHR (adjusted hazard ratio); 0.72, 95\% Cl: 0.69-0.74]. This finding was in line with the research finding from Canada[14]. This is because of the fact that breastfeeding increases insulin sensitivity and improves glucose metabolism to women [15].

The risk of diabetes mellitus increases by $4 \%$ per year increase in the age of the women [AHR; $1.04,95 \%$ $\mathrm{Cl}$ : 1.03-1.05]. This finding agrees with research from the USA [16]. This is because of the fact that older age increases the resistance of insulin and impaired pancreatic islet functions [17].

A unit increase in the parity of the women increases the probability of DM by $14 \%$ [AHR; $1.14,95 \% \mathrm{Cl}$ : 1.07-1.21]. This result agrees with evidence from China [18]. This is due to the reason that high parity is associated with higher maternal age that increases the resistance of insulin[19].

Regular physical exercise decreases the risk of DM by 2.22 folds [AHR; $0.45,95 \% \mathrm{Cl}: 0.37-0.55$ ]. This finding strengthens the previous research conclusion [20]. This is due to the effects of exercise in preventing obesity and increasing the endocrine actions of insulin [21]. 
The family history of DM increases the risk of acquiring DM by two folds [AHR; 2.04, 95\% Cl: 1.76-2.37]. This finding agrees with researcher's work from Nepal [22]. This is due to the familial tendency in insulin secretory defects [23].

Stillbirth increases the risk of DM by $67 \%$ [AHR; $1.67: 95 \% \mathrm{Cl}: 1.34-2.07]$. This finding agrees with finding from Italy [24]. This is due to the effects of stillbirth on disturbing the normal endocrine action of women [25].

The hazard of DM increases by 2.6 folds in the presence of abortion [AHR; $2.64,95 \% \mathrm{Cl}: 2.25-3.09$ ]. The finding was in line with the expert's work from China [26]. This is due to the multi-system effects of abortion on women's health, like cardiovascular problems which finally make the women become obese and acquire insulin resistance [27].

The main limitation of this study was a failure to identify the effects of gestational diabetes on the progression of other chronic illnesses.

\section{Conclusion}

The progression of GDM to DM was very high and special follow up should be implemented for women with a history of abortion, stillbirth, and family history of DM.

\section{Abbreviation}

AHR-Adjusted hazard ratio

ANC- antenatal care

Cl-Confidence interval

DM- diabetes mellitus

GDM- gestational diabetes mellitus

HbA1c- hemoglobin A 1c

HR- hazard ratio

IPAQ- International Physical Activity Questionnaire tool

$\mathrm{Mg} / \mathrm{dl}$ - milligram per-deciliter

ML- Milliliter

SD-Standard deviation 
SOP-standard operating procedures

WHO- World health organization

\section{Declarations}

\section{Ethics approval and consent to participate}

Ethical clearance was obtained from Bahir Dar University College of medicine and health science ethical review board with an ethical approval number of CMHS/IRB/93/2014. A support letter was obtained from the Amhara regional state health bureau. A permission letter was obtained from each hospital. Written informed consent was obtained from each study participant. Pretest and posttest counseling was given for each study participant. A study participant diagnosed with DM was linked to the chronic care.

\section{Consent for publication}

Not applicable

\section{Availability of Data and Materials}

The datasets used and/or analyzed during the current study are available from the corresponding author on reasonable request.

Competing interest

The authors declare that they have no competing interests.

\section{Funding}

This research work was financially supported by the University of Bahir dar and Federal democratic republic of Ethiopia ministry of health. The funder has no role in the design of the study and collection, analysis, and interpretation of data and in writing the manuscript.

\section{Author contribution}

BEF and TEF conceived the experiment; BEF, MBK, WGA, AG, and TEF performed the experiment, BEF, TEF, WGA, AAN, HAE and DA plan the data collection process, BEF, MBK, DA WGA and TEF analyzed and interpreted the data. BEF, TEF, WGA, AG, and AAN wrote the manuscript and all authors approved the final draft for publication.

\section{Acknowledgements}


We would like to acknowledge the Amhara regional state health bureau for their unreserved contribution during the field work. Our heartfelt appreciation also goes to the referral hospitals for their cooperation during the data collection process. At last not least, we would like to thanks all organizations and individuals that had an input for this work.

\section{References}

1. Chiefari E, Arcidiacono B, Foti D, Brunetti A. Gestational diabetes mellitus: an updated overview. J Endocrinol Invest. 2017;40(9):899-909.

2. Amiri M. Diabetes mellitus type 2; an international challenge. Annals of Research in Dialysis. 2016;1.

3. Amiri M, Hosseini SM, Maghsoudi R. Diabetes mellitus type 1; is it a global challenge. Acta Epidemioendocrinologica. 2016;1(1).

4. World Health Organization. Diabetes. Genera. Swetherland: WHO; 2018.

5. Gosmanov AR, Gosmanova EO, Kitabchi AE. Hyperglycemic crises: diabetic ketoacidosis (DKA), and hyperglycemic hyperosmolar state (HHS). Endotext [Internet]: MDText. com, Inc.; 2018.

6. Heydari I, Radi V, Razmjou S, Amiri A. Chronic complications of diabetes mellitus in newly diagnosed patients. International Journal of Diabetes Mellitus. 2010;2(1):61-3.

7. Standards of Medical Care in Diabetes-2014. Diabetes Care 2014;37(Suppl. 1):S14-S80 < br/>Diagnosis and Classification of Diabetes Mellitus. Diabetes Care 2014;37(Suppl. 1):S81-S90. Diabetes Care. 2014;37(3):887-. doi: 10.2337/dc14-er03.

8. Rhee MK, Ho Y-L, Raghavan S, Vassy JL, Cho K, Gagnon D, et al. Random plasma glucose predicts the diagnosis of diabetes. PloS one. 2019;14(7).

9. Sjostrom M, Ainsworth B, Bauman A, Bull F, Hamilton-Craig C, Sallis J. Guidelines for data processing analysis of the International Physical Activity Questionnaire (IPAQ)-Short and long forms. 2005.

10. Damm P, Houshmand-Oeregaard A, Kelstrup L, Lauenborg J, Mathiesen ER, Clausen TD. Gestational diabetes mellitus and long-term consequences for mother and offspring: a view from Denmark. Diabetologia. 2016;59(7):1396-9.

11. Pedersen AB, Mikkelsen EM, Cronin-Fenton D, Kristensen NR, Pham TM, Pedersen L, et al. Missing data and multiple imputation in clinical epidemiological research. Clinical epidemiology. 2017;9:157.

12. Herath $\mathrm{H}$, Herath $\mathrm{R}$, Wickremasinghe R. Gestational diabetes mellitus and risk of type 2 diabetes 10 years after the index pregnancy in Sri Lankan women-A community based retrospective cohort study. PloS one. 2017;12(6).

13. Pappa KI, Gazouli M, Economou K, Daskalakis G, Anastasiou E, Anagnou NP, et al. Gestational diabetes mellitus shares polymorphisms of genes associated with insulin resistance and type 2 diabetes in the Greek population. Gynecol Endocrinol. 2011;27(4):267-72.

14. Martens PJ, Shafer LA, Dean HJ, Sellers EA, Yamamoto J, Ludwig S, et al. Breastfeeding initiation associated with reduced incidence of diabetes in mothers and offspring. Obstetrics Gynecology. 2016;128(5):1095-104. 
15. Yasuhi I, Yamashita H, Maeda K, Nomiyama M, Mizunoe T, Tada K, et al. High-intensity breastfeeding improves insulin sensitivity during early post-partum period in obese women with gestational diabetes. Diab/Metab Res Rev. 2019;35(4):e3127.

16. Kasher-Meron M, Grajower MM. Preventing progression from gestational diabetes mellitus to diabetes: A thought-filled review. Diab/Metab Res Rev. 2017;33(7):e2909.

17. Bacos K, Gillberg L, Volkov P, Olsson AH, Hansen T, Pedersen O, et al. Blood-based biomarkers of ageassociated epigenetic changes in human islets associate with insulin secretion and diabetes. Nature communications. 2016;7(1):1-13.

18. Guo P, Zhou Q, Ren L, Chen Y, Hui Y. Higher parity is associated with increased risk of type 2 diabetes mellitus in women: a linear dose-response meta-analysis of cohort studies. Journal of Diabetes its Complications. 2017;31(1):58-66.

19. Kim JH, Lee SJ. Parity and increased risk of insulin resistance in postmenopausal women: the 2010 Korean National Health and Nutrition Examination Survey. Menopause. 2017;24(7):832-7.

20. Schuler G, Linke A. Diabetes and exercise. Type 2 Diabetes: CRC Press; 2016. p. 87-96.

21. Melmer A, Kempf P, Laimer M. The Role of Physical Exercise in Obesity and Diabetes. Praxis. 2018;107(17-18):971-6. doi:10.1024/1661-8157/a003065. PubMed PMID: 30131033.

22. Shrestha B, Nepal B, Shakya YL, Regmi B. Life style factors associated with the risk of type 2 diabetes mellitus. Grande Medical Journal. 2019;1(2):77-83.

23. Elbein S, Sorensen L. Genetic variation in insulin receptor $\beta$-chain exons among members of familial type 2 (non-insulin-dependent) diabetic pedigrees. Diabetologia. 1991;34(10):742-9.

24. Pintaudi B, Lucisano G, Pellegrini F, D’Ettorre A, Lepore V, De Berardis G, et al. The long-term effects of stillbirth on women with and without gestational diabetes: a population-based cohort study. Diabetologia. 2015;58(1):67-74.

25. Gingrich J, Ticiani E, Veiga-Lopez A. Placenta Disrupted: Endocrine Disrupting Chemicals and Pregnancy. Trends in Endocrinology \& Metabolism. 2020.

26. Liu B, Song L, Li H, Zheng X, Yuan J, Liang Y, et al. History of spontaneous miscarriage and the risk of diabetes mellitus among middle-aged and older Chinese women. Acta diabetologica. 2018;55(6):579-84.

27. Asgharvahedi F, Gholizadeh L, Siabani S. The risk of cardiovascular disease in women with a history of miscarriage and/or stillbirth. Health Care Women Int. 2019;40(10):1117-31.

\section{Figures}




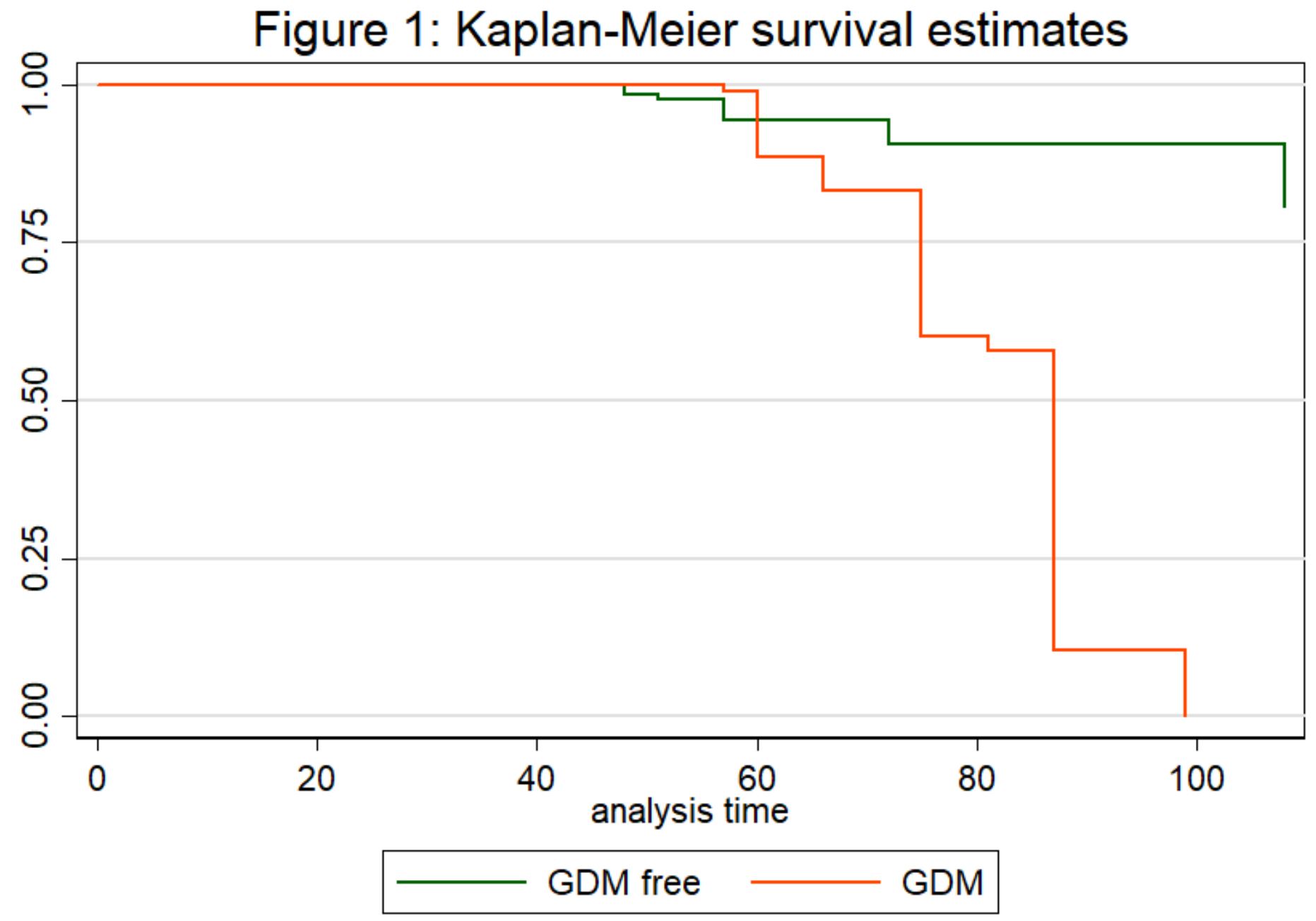

Figure 1

Kaplan Meier survival estimates

\section{Supplementary Files}

This is a list of supplementary files associated with this preprint. Click to download.

- STROBEchecklistcohort.docx 